\title{
Axonal Translation of $\beta$-Catenin Regulates Synaptic Vesicle Dynamics
}

\author{
Anne Marion Taylor, ${ }^{1}$ Jason Wu, ${ }^{1}$ Hwan-Ching Tai, ${ }^{2}$ and Erin M. Schuman ${ }^{3,4}$ \\ ${ }^{1}$ University of North Carolina at Chapel Hill and North Carolina State University, Joint Department of Biomedical Engineering, Chapel Hill, North Carolina \\ 27599, ${ }^{2}$ California Institute of Technology, Division of Biology, Pasadena, California 91125, ${ }^{3}$ Max Planck Institute for Brain Research, 60438 Frankfurt, \\ Germany, and ${ }^{4}$ Cluster of Excellence for Macromolecular Complexes, Goethe University, 60438 Frankfurt, Germany
}

\begin{abstract}
Many presynaptic transcripts have been observed in axons, yet their role in synapse development remains unknown. Using visually and pharmacologically isolated presynaptic terminals from dissociated rat hippocampal neurons, we found that ribosomes and $\beta$-catenin mRNA preferentially localize to recently formed boutons. Locally translated $\beta$-catenin accumulates at presynaptic terminals, where it regulates synaptic vesicle release dynamics. Thus, local translation of $\beta$-catenin is a newly described mechanism for axons to independently functionalize nerve terminals at great distances from cellular somata.
\end{abstract}

\section{Introduction}

Proper brain development requires that long projecting axons form presynaptic boutons quickly and with little involvement from the somatic compartment (McAllister, 2007; Andreae et al., 2012). Evidence from Aplysia and rat hippocampal neurons supports a role for local translation in regulating functional bouton assembly (Schacher and $\mathrm{Wu}, 2002$; Lyles et al., 2006; Sebeo et al., 2009), providing a rapid and spatially restricted mechanism to nucleate synaptic vesicle release sites. Many presynaptic transcripts have been detected in isolated mature axons (defined here as those capable of forming synapses) (Taylor et al., 2009; Zivraj et al., 2010), but their role in presynaptic assembly remains unclear. Furthermore, the detection of translational machinery in central mammalian axons beyond early outgrowth is lacking.

\section{Materials and Methods}

Reagents. We obtained N-(3-trimethylammoniumpropyl)-4-(6-(4-(diethylamino)phenyl)hexatrienyl)pyridinium dibromide (FM 5-95) from Invitrogen $(10 \mu \mathrm{M})$; 6-cyano-7-nitroquinoxaline-2,3-dione disodium (CNQX disodium salt) $(20 \mu \mathrm{M})$ and D-(-)-2-amino-5-phosphonopentanoic acid (DAP5) $(50 \mu \mathrm{M})$ from Tocris Bioscience; Advasep-7 from Biotium (1 mM); high molecular weight poly-D-lysine (PDL) from either BD Biosciences or Millipore; cycloheximide (CHX) from Sigma-Aldrich (50 $\mu \mathrm{M})$; Accell siRNA

\footnotetext{
Received June 21, 2012; revised Jan. 14, 2013; accepted Feb. 7, 2013.

Author contributions: A.M.T. designed research; A.M.T., J.W., and H.-C.T. performed research; A.M.T. analyzed data; A.M.T. and E.M.S. wrote the paper.

We thank Nicole Calakos (Duke University), Dan Albaugh (University of North Carolina) and Richard Weinberg (University of North Carolina) for helpful discussions and comments on the manuscript. We thank Naomi McArthur (California Institute of Technology) and Graham Mulvany (University of North Carolina) for participation in data analysis. A.M.T. acknowledges support from the Eunice Kennedy Shriver National Institute of Child Health \& Human Development (K12HD073945) and the Simons Foundation (SFARI \#236390 to A.M.T.). The content is solely the responsibility of the authors and does not necessarily represent the official views of the National Institutes of Health. A.M.T. is a cofounder of Xona Microfluidics.

Correspondence should be addressed to either of the following: Anne Marion Taylor at the above address, E-mail: amtaylor@unc.edu; or Erin Schuman at the above address, E-mail: schumane@brain.mpg.de.

DOI:10.1523/JNEUROSCI.2944-12.2013

Copyright $\odot 2013$ the authors $\quad 0270-6474 / 13 / 335584-06 \$ 15.00 / 0$
}

(SMARTpool) for $\beta$-catenin (rat Ctnnb1, ORF, E-100628-01-0010) and Accell nontargeting siRNA (D-001910-01-05 or D001910-04-05) (3 $\mu \mathrm{M})$ from Thermo Fisher Scientific; and Sylgard 184 poly(dimethylsiloxane) (PDMS) from Dow Corning.

Microfluidic chambers. PDMS microfluidic chambers were replica molded from microfabricated master molds as described previously (Taylor et al., 2005). All experiments used chambers with $900-\mu \mathrm{m}-$ long microgroove-embedded barriers. Approximately 50,000 hippocampal cells were plated into the cell body side of the chambers.

PDL-coated beads. Surfactant-free white aliphatic amine latex microspheres $4-5 \mu \mathrm{m}$ in diameter from Invitrogen were incubated at $37^{\circ} \mathrm{C}$ in $40 \mu \mathrm{g} / \mathrm{ml}$ for $30 \mathrm{~min}$ to $2 \mathrm{~h}$, rinsed twice in sterile water, and then diluted in neurobasal medium (Invitrogen) supplemented with B27 (Invitrogen) and glutamax (Invitrogen).

Hippocampal cultures. Hippocampal cultures were prepared from embryonic day 17-18 Sprague Dawley embryos of either sex or Sprague Dawley postnatal day $0-3$ pups of either sex as described previously (Aakalu et al., 2001; Taylor et al., 2005). Similar results were seen with both preparations.

Immunocytochemistry. The PDMS microfluidic chambers were peeled off and the bottom coverglass fixed with $4 \%$ paraformaldehyde in PBS containing $40 \mathrm{mg} / \mathrm{ml}$ sucrose, $1 \mu \mathrm{MgCl}_{2}$, and $0.1 \mu \mathrm{M} \mathrm{CaCl}_{2}$ for $20-30$ min. The cultures were permeabilized in $0.25 \%$ Triton X-100 for $15 \mathrm{~min}$ and then blocked in PBS with $10 \%$ goat serum for 15 min. Primary antibodies were diluted in PBS with 1\% goat serum and incubated for $1 \mathrm{~h}$ at room temperature. The following antibodies were used: mouse antiBassoon (SAP7F407) (1:1000; Enzo Life Sciences), mouse anti-rRNA (Y10b) (1:250; Thermo Fisher Scientific), rabbit anti- $\beta$-catenin (Cterminus) (1:500; Invitrogen), rabbit anti- $\beta$-tubulin (1:1000; Abcam), and chicken anti- $\beta$-tubulin (1:1000; Aves Labs). We used AlexaFluor goat anti-mouse, anti-rabbit, and anti-chicken antibodies conjugated to fluorophores with $488 \mathrm{~nm}, 568 \mathrm{~nm}$, or $633 \mathrm{~nm}$ excitation wavelengths (1:500; Invitrogen).

Fluorescence in situ hybridization. Procedures were performed as described previously using Panomics QuantiGene ViewRNA reagents and probe sets (Taylor et al., 2009). Antisense probe sets were designed for Ctnnb1 (accession number NM_053357) covering 8-1254 bp, Arc (accession number NM_019361), and 18S ribosomal RNA (type 1, accession number X03205). The control probe set was designed using the sense sequence for the Ctnnb1 (NM_053357). 
A

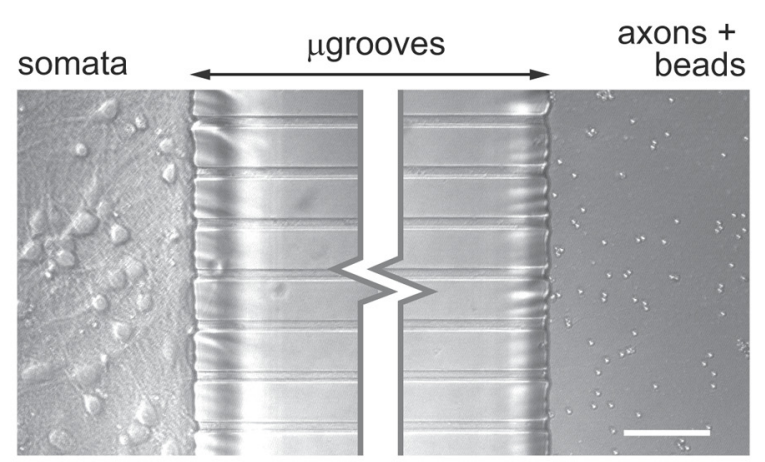

C

$15 \mathrm{~min}$

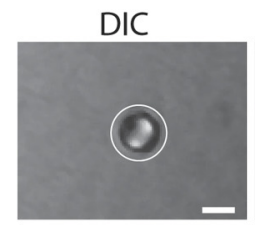

$3 \mathrm{~h}$

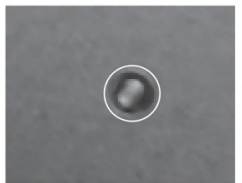

24h
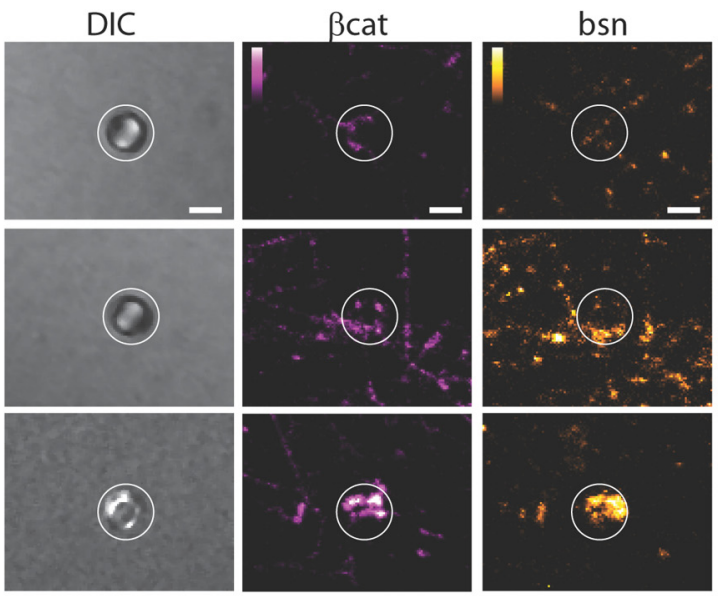

$48 h$
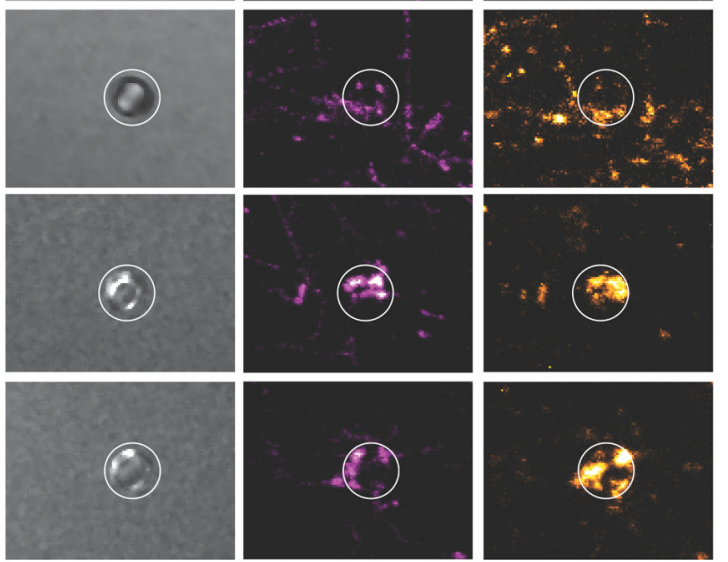

F

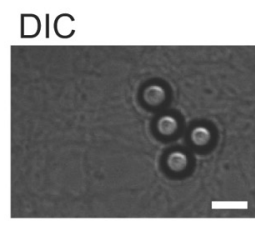

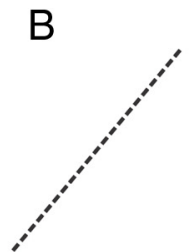
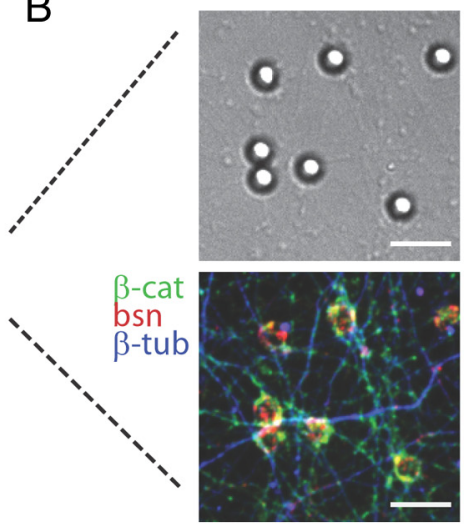

D

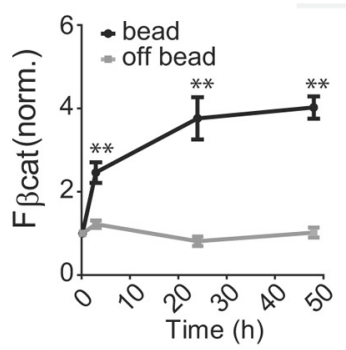

E

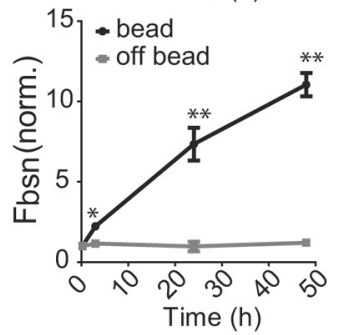

$G$

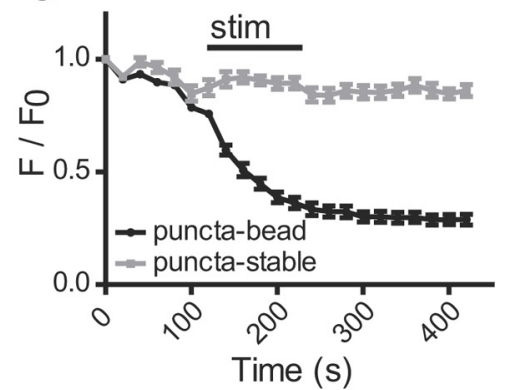

Figure 1. PDL-coated beads induce the formation of functional presynaptic terminals within $24 \mathrm{~h}$. $A$, Differential interference contrast (DIC) image of hippocampal neurons cultured in microfluidic chambers with PDL-coated beads added to the axonal compartment. Scale bar, $75 \mu \mathrm{m}$. B, DIC and merged immunofluorescence images of $\beta$-catenin, Bassoon, and $\beta$-tubulin III within the axonal compartment. Beads were incubated within axonal compartment for $24 \mathrm{~h}$ before fixation. Scale bar, $10 \mu \mathrm{m}$. $\boldsymbol{C}-\boldsymbol{E}$, Time course of $\beta$-catenin (magenta) and Bassoon (orange) immunolabeling following addition of beads to the axonal compartment. White circles encompass bead location. Color lookup tables are shown. Scale bar, $5 \mu \mathrm{m}$. Quantification of fluorescence levels for $\beta$-catenin (D) and bassoon ( $\boldsymbol{E}$ ) within ROls surrounding beads and ROls away from the bead (off bead) (15 min, $n=210 ; 3 \mathrm{~h}, n=107 ; 24 \mathrm{~h}, n=22 ; 48 \mathrm{~h}, n=98)$. Data were normalized to average mean pixel value for the 15 min time point. Significance was determined using two-way ANOVA with Bonferroni multiple-comparisons ${ }^{*} p<0.05,{ }^{* *} p<0.001$ versus off-bead. Error bars, SEM. $F, \mathbf{G}, \mathrm{FM}$ 5-95 loading and unloading $24 \mathrm{~h}$ after addition of beads. Fluorescence images are inverted for improved visualization of puncta $(\boldsymbol{F})$. Arrow indicates stable puncta, which do not unload during stimulation. Dynamics of FM 5-95 labeling around bead (G); puncta localized to the bead $(n=16)$ compared with stable puncta $(n=8) . p<0.05$ beginning at 120 s. Scale bar, $5 \mu \mathrm{m}$.

siRNA experiments. We used commercially available cell-permeable siRNA, which has been used previously for selective knockdown in axons (Sebeo et al., 2009). We used Accell rat Ctnnb1 SMARTpool siRNA (E-100628-01) and Accell nontargeting siRNA for control siRNA (D001910-01, D-001910-04). siRNA was applied at a final concentration of $2.4 \mathrm{~nm}$ for at least $4 \mathrm{~d}$ before fixing for immunocytochemistry (ICC) or imaging with FM dye.

FM dye experiments. Cell culture media were first replaced with HEPES-buffered solution (HBS; $119 \mathrm{~mm} \mathrm{NaCl}, 5 \mathrm{~mm} \mathrm{KCl}, 2 \mathrm{mM} \mathrm{CaCl}_{2}, 2$ $\mathrm{mm} \mathrm{MgCl}_{2}, 30 \mathrm{~mm}$ glucose, $10 \mathrm{~mm}$ HEPES) and allowed to recover for at least 30 min. FM dye loading solution containing $10 \mu \mathrm{M} \mathrm{FM} \mathrm{5-95,} 20 \mu \mathrm{M}$ CNQX, $50 \mu \mathrm{M}$ D-AP5, and high $\mathrm{KCl}(90 \mathrm{~mm} \mathrm{KCl}, 34 \mathrm{~mm} \mathrm{NaCl}, 2 \mathrm{~mm}$ $\mathrm{CaCl}_{2}, 2 \mathrm{~mm} \mathrm{MgCl}$, $30 \mathrm{~mm}$ glucose, $10 \mathrm{~mm}$ HEPES) was added to the microfluidic platforms for $1 \mathrm{~min}$. Media were then replaced with $10 \mu \mathrm{M}$ FM 5-95 in HBS for 1 min to allow for endocytosis of the dye following stimulation. The chambers were rinsed three times $(\sim 1 \mathrm{~min}$ each time) with a high- $\mathrm{Mg}^{2+}$, low- $\mathrm{Ca}^{2+}$ solution $(106 \mathrm{~mm} \mathrm{NaCl}, 5 \mathrm{~mm} \mathrm{KCl}, 0.5 \mathrm{~mm}$ $\mathrm{CaCl}_{2}, 10 \mathrm{~mm} \mathrm{MgCl}_{2}, 30 \mathrm{~mm}$ glucose, $10 \mathrm{~mm}$ HEPES) containing $1 \mathrm{~mm}$ Advasep-7. The chambers were rinsed another three times $(\sim 1$ min each time) with HBS containing $20 \mu \mathrm{M} C N Q X$ and $50 \mu \mathrm{M}$ D-AP5. Unloading 
A
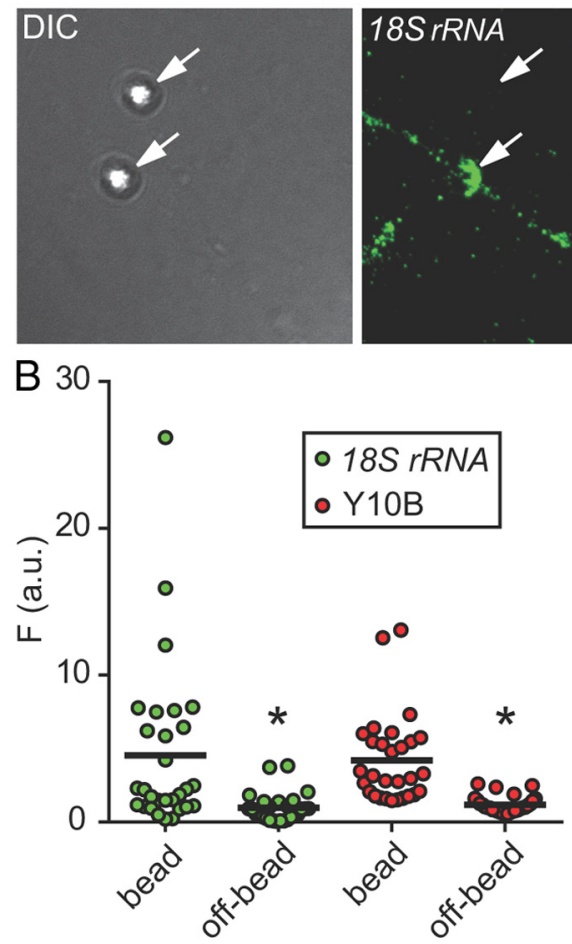

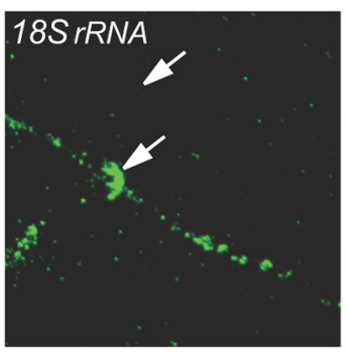

C
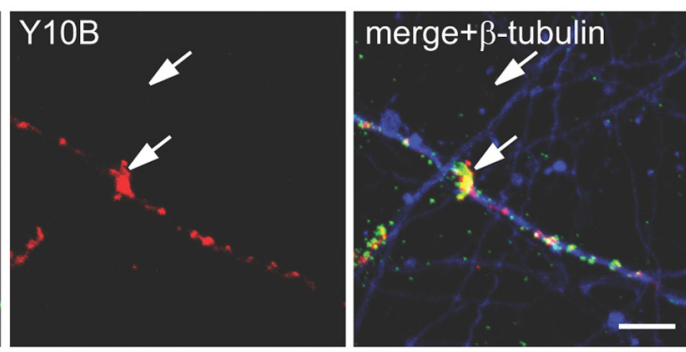

D

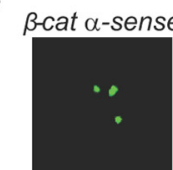

sense

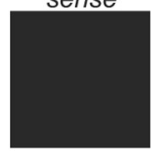

Arc $\alpha-\operatorname{sen}$

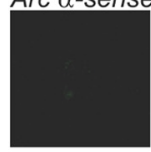

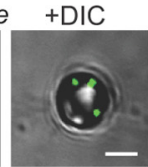

$+\mathrm{DIC}$

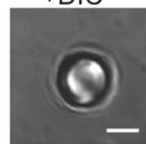

$+\mathrm{DIC}$

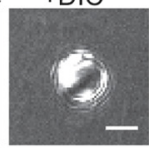

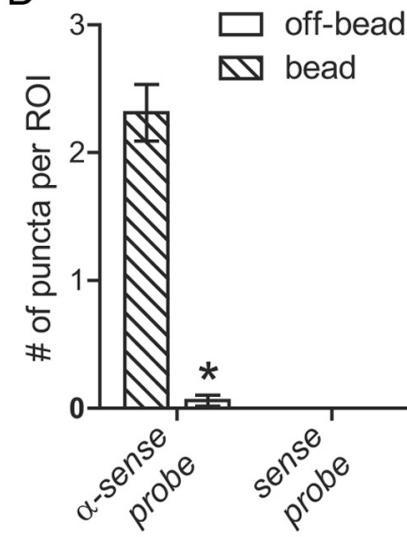

Figure 2. Ribosomal RNA and $\beta$-catenin mRNA localize to newly formed presynaptic terminals. A, Fluorescence in situ hybridization (FISH) for 18S ribosomal RNA and immunofluorescence for $5.8 \mathrm{~S}$ ribosomal RNA (Y10B, red) colocalize within isolated axons and accumulate around bead-induced presynaptic terminals at $24 \mathrm{~h}$ following bead addition. Scale bar, $10 \mu \mathrm{m}$. $\boldsymbol{B}$, Average fluorescence intensity of $18 \mathrm{~S}$ rRNA FISH and Y10B immunofluorescence within bead ROIs $(n=29)$ and off-bead axon ROIs $(n=29) .{ }^{*} p<0.001$. C, $\beta$-Catenin mRNA FISH signal within bead ROls compared with a sense control probe set and a probe set for the dendritically targeted mRNA, Arc. Scale bar, $3 \mu \mathrm{m}$. D, Quantification of FISH signals for $\beta$-catenin mRNA probe sets within bead ROls (antisense, $n=32$; sense, $n=11$ ) and off-bead ROls (antisense, $n=33$; sense, $n=15$ ) ${ }^{*} p<0.001$. Error bars, SEM.

was performed using electrical field stimulation of the axonal compartment. For electrical stimulation, positive and negative electrodes were placed in each well of the axonal compartment. For Figure $1 F, G$, we stimulated the axonal compartment using a function generator (HP $3312 \mathrm{~A}$ ) with the following settings: $15 \mathrm{~V}, 2 \mathrm{~ms}$ pulse-width square pulse, $10 \mathrm{~Hz}$ for $2 \mathrm{~min}$. For Figure 4, we used an AD Instruments two-channel stimulus generator (STG4002) in current mode with an asymmetric waveform $(-480 \mu \mathrm{A}$ for $1 \mathrm{~ms}$ and $+1600 \mu \mathrm{A}$ for $0.3 \mathrm{~ms})$ at $20 \mathrm{~Hz}$ for 600 pulses. $Z$-stacks ( 40 slices) were captured every $15 \mathrm{~s}$. At least five baseline images were acquired before electrically stimulating axons.

Microscopy. Images were acquired using either an Olympus IX-70 laser scanning confocal microscope or a spinning disk confocal imaging system (CSU-X1, Yokogawa) configured for an Olympus IX81 zero-drift microscope (Revolution XD, Andor Technology). For the laser point scanning confocal, we used an Ar ion laser (488 nm excitation) with long-pass (BA510IF) and short-pass (BA550RIF) filters; a Kr laser (568 $\mathrm{nm}$ and $647 \mathrm{~nm}$ excitation) with long-pass (BA585IF) and bandpass (605BP) filters for $568 \mathrm{~nm}$ fluorophores, and long-pass (BA585IF) and bandpass (700BP) filters for $647 \mathrm{~nm}$ fluorophores. For the spinning disk confocal imaging system, light excitation was provided by $50 \mathrm{~mW}, 488$ $\mathrm{nm} ; 50 \mathrm{~mW}, 561 \mathrm{~nm}$; and $100 \mathrm{~mW}, 640 \mathrm{~nm}$ lasers. The following bandpass emission filters (BrightLine, Semrock) were used: 525/30 nm (TRF525-030), 607/36 nm (TR-F607-036), 685/40 nm (TR-F685-040). For FM 5-95 imaging, we used a spinning disk confocal imaging system with excitation at $561 \mathrm{~nm}$ (25\% intensity) and with the $685 / 40 \mathrm{~nm}$ emission filter. We used $2 \times 2$ binning to reduce the laser intensity and acquisition time for each frame. Each $z$-stack was obtained in $\sim 5 \mathrm{~s}$.

Image processing and analysis. Confocal slices were sum projected in ImageJ and converted to 8-bit depth. Mean pixel values were recorded using either the entire frame or bead ROIs (sufficient to encompass bead). For off-bead ROIs, random locations without beads, but with axons, were selected within each frame. Fluorescence in situ hybridization (FISH) puncta were quantified by first thresholding to minimum pixel value of 50 and then counting particles $>0.044 \mu \mathrm{m}^{2}$ within ROIs. For the FM image analysis, we thresholded the first frame of the $z$-stack to a minimum pixel value of 10 . We analyzed puncta $>2$ pixels $^{2}$ contained within each bead ROI (31 pixel diameter) and measured the intensity of each of these puncta throughout the registered stack. The intensity of each puncta was normalized to the frame preceding stimulation and slope normalized to baseline. Puncta that unloaded $>5 \%$ after $1 \mathrm{~min}$ were classified as unloaded and were included in the analysis. We used curve fitting in ImageJ to estimate the time constant, $\tau$, for each puncta fitting to "exponential with offset." $\tau$ values $>360$ s (longer than the experiment run time) were excluded from the analysis and considered to be nonreleasing.

Statistics. Statistical analyses were performed using GraphPad Prism. When $>2$ variables were involved, significance was determined using two-way ANOVA and Bonferroni multiple-comparisons post hoc test unless otherwise noted. Two-tailed unpaired Student's $t$ test was used when comparing means for two conditions.

\section{Results}

To visualize low levels of RNA and protein within presynaptic terminals, we used a culture system that allows presynaptic terminals to form in isolation, thereby eliminating overwhelming somatic and dendritic signals. We presented mature $(>10 \mathrm{~d}$ in culture) hippocampal axons, compartmentalized via a microfluidic chamber, with PDL-coated beads that induce functional presynaptic terminal formation (Taylor et al., 2005; Lucido et al., 2009) (Fig. 1A,B). PDL-coated beads have previously been shown to induce the accumulation of many integral presynaptic proteins, including $\mathrm{N}$-cadherin (Lucido et al., 2009). To validate the formation of functional presynaptic terminals, we analyzed the specific accumulation of presynaptic proteins within bead 
A
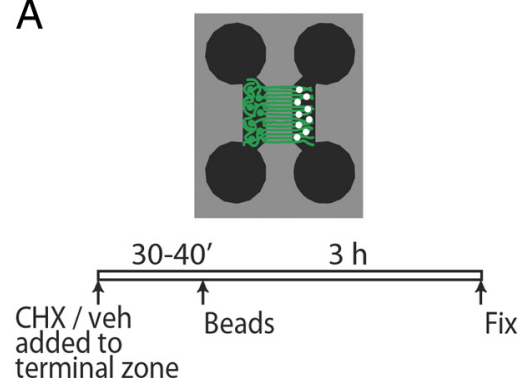

terminal zone

C

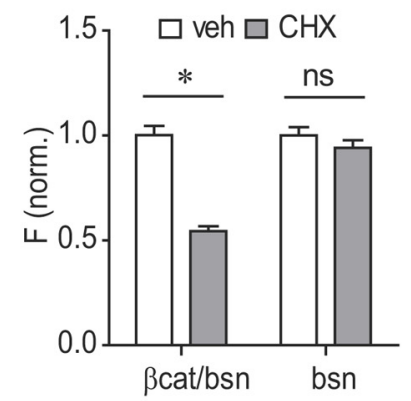

F

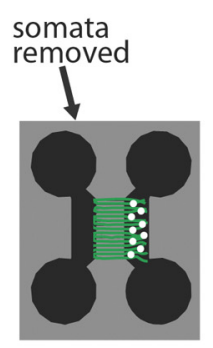

B
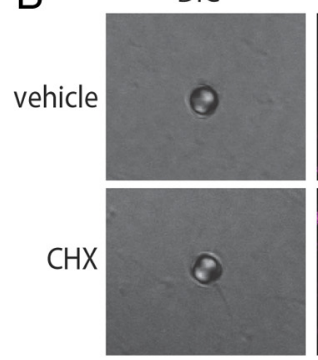

D

E
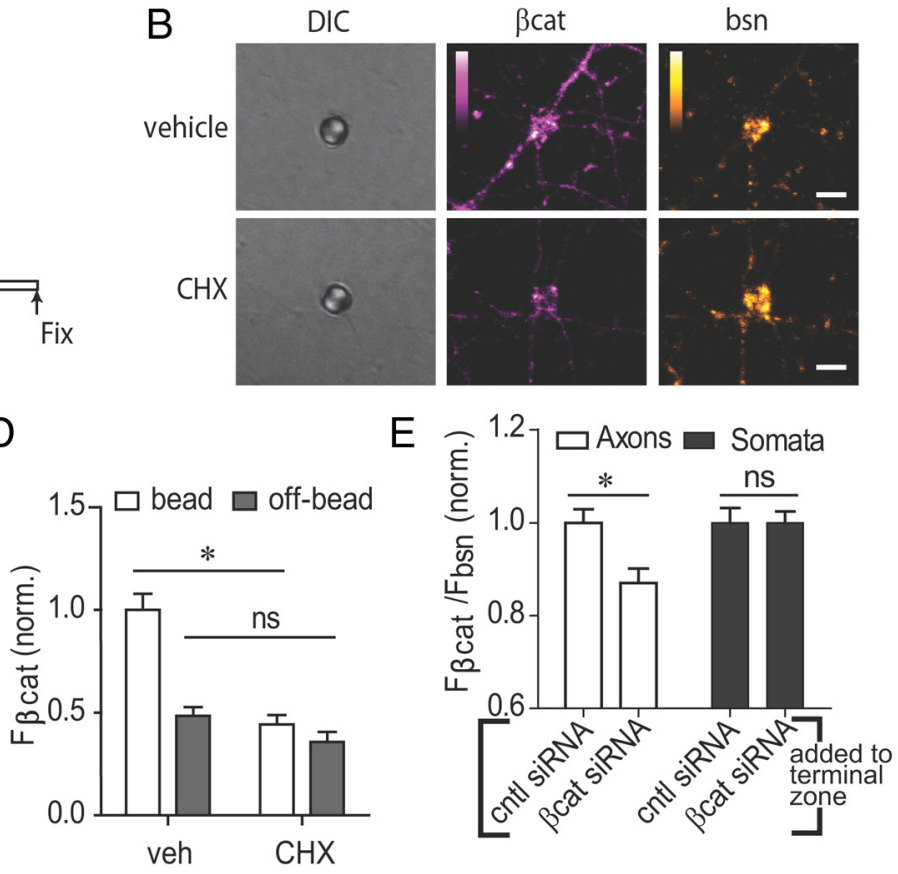

$\mathrm{H}$
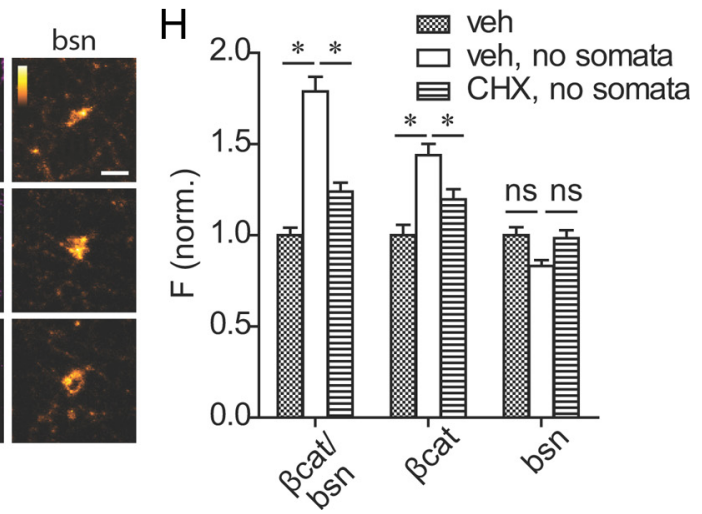

Figure 3. Presynaptic accumulation of $\beta$-catenin requires local translation. $\boldsymbol{A}$, Experimental design. $\boldsymbol{B}$, Representative images of PDL-coated beads coimmunolabeled for $\beta$-catenin (magenta) and Bassoon (orange) within the axonal compartment in vehicle and CHX conditions. C, Quantification showing $\beta$-catenin/Bassoon intensity ratios within beads ROIs for vehicle ( $n=472$ ) and $C H X$ ( $n=548$ ) conditions within the axonal compartment. Mean Bassoon fluorescence intensity for vehicle (veh, $n=701)$ and CHX ( $n=805)$. $D$, Average mean pixel value surrounding bead (vehicle, $n=121 ; \mathrm{CHX}, n=84$ ) compared with off-bead (vehicle, $n=104 ; \mathrm{CHX}, n=67)$. $\boldsymbol{E}, \beta$-Catenin/Bassoon intensity fraction with control and $\beta$-catenin siRNA applied to the axonal compartment. Average pixel value of each frame ( 2 chambers, 10 frames per chamber) was used from both the axonal and somatic compartments. * $p<0.01$. All values are normalized to average intensity for vehicle condition. $\boldsymbol{F}-\boldsymbol{H}, \beta$-Catenin and Bassoon fluorescence intensity around beads compared in the presence or absence of somata and CHX. $\mathbf{G}$, Somata were removed and CHX was immediately applied to the axon terminals; the remaining events progressed as depicted in the timeline shown in $\boldsymbol{A}$. Scale bar, $5 \mu \boldsymbol{m}$. $\boldsymbol{H}$, Bar chart showing average fluorescence of $\beta$-catenin relative to Bassoon, $\beta$-catenin alone, and Bassoon alone within each bead ROI, for vehicle $(n=288)$, cells removed with vehicle added to axonal compartment $(n=366)$, and cells removed with CHX added to axonal compartment $(n=267) .{ }^{*} p<0.05$. Error bars, SEM.

ROIs and compared them to axonal regions that do not contain beads at $15 \mathrm{~min}, 3 \mathrm{~h}, 24 \mathrm{~h}$, and $48 \mathrm{~h}$ following bead addition (Fig. $1 C-E)$. Immunolabeled $\beta$-tubulin did not accumulate at bead ROIs after $24 \mathrm{~h}$, verifying specificity of protein accumulation at bead contact sites (mean fluorescence within bead ROIs, $27.93 \pm$ 2.25 a.u., $n=40$ measurements; mean fluorescence within OFFbead ROIs, $28.02 \pm 2.02$ a.u., $n=40$; $p=0.98)$. We next used a lipophilic FM dye (5-95) to verify that the terminals were functional (Fig. $1 F, G$ ). Together, these data confirmed that the addition of the beads induce the formation of presynaptic terminals (hereafter we refer to the boutons that form within bead ROIs as nascent presynaptic terminals).

To determine whether these axons have the capacity for local translation, we labeled rRNA using both FISH for $18 S$ rRNA and ICC using an anti-rRNA antibody (overlap coefficient, 0.97; Fig. $2 A$ ). While many axons were positive for rRNA labeling, others did not show detectable signal, suggesting that only a subpopulation of axons contain ribosomal RNA. Ribosomal RNA levels were significantly higher within bead ROIs than in random axon ROIs (Fig. 2B), suggesting that local translation is enhanced within developing presynaptic terminals.

$\beta$-Catenin mRNA is found in both developing and mature central axons (Kundel et al., 2009; Taylor et al., 2009). We observed a significant accumulation of $\beta$-catenin protein within bead ROIs compared with nonbead axonal regions, suggesting a presynaptic function for locally expressed $\beta$-catenin. $\beta$-Catenin is known to have a role in synapse assembly, where it has been observed to regulate synaptic vesicle pool assembly (Bamji et al., 2003). To examine whether locally translated $\beta$-catenin contributes to synapse formation, we used high-resolution FISH and found that $\beta$-catenin mRNA preferentially localized to newly established presynaptic terminals (Fig. 2C,D). Control probes, in- 
cluding $\beta$-catenin sense probes and Arc mRNA probes, showed no signal (Fig. 2C,D).

Next, to determine whether $\beta$-catenin is locally synthesized during presynaptic terminal formation, we examined $\beta$-catenin using ICC in the presence or absence of a locally applied protein synthesis inhibitor (CHX) (Fig. 3A-D). In the presence of vehicle, there was abundant $\beta$-catenin present in the vicinity of the bead. When CHX was locally applied, however, we observed a significant reduction in $\beta$-catenin levels associated with the bead (Fig. $3 C$ ) without any accompanying change in the somatic levels of $\beta$-catenin (data not shown). Bassoon levels, by comparison, did not exhibit any change ( $p=$ 0.265). We used Bassoon as an internal control because it rapidly accumulates at presynaptic terminals and its mRNA is not detectable in these axons and thus should not be locally translated (Fejtova et al., 2009; Taylor et al., 2009). The CHXmediated loss of $\beta$-catenin within axons occurred specifically at bead locations (Fig. 3D). To confirm that the somata are not the source of this $\beta$-catenin, we performed another experiment with the somata removed, and observed an equivalent fold reduction in $\beta$-catenin with axonally applied CHX compared with vehicle (Fig. $3 F-H$ ). To determine whether axonal $\beta$-catenin mRNA is the source of the new $\beta$-catenin protein, we used a cell-permeable siRNA designed for $\beta$-catenin and applied this selectively to the axonal compartment. We observed a significant reduction in $\beta$-catenin protein expression within the axonal compartment compared with control siRNA and no reduction in the somatic compartment (Fig. $3 E$ ). Together, these data show that $\beta$-catenin is locally translated within axons during presynaptic terminal formation.

We next examined the functional role that local $\beta$-catenin translation plays in synaptic vesicle release. We used a lipophilic FM dye (5-95) to evaluate synaptic vesicle unloading dynamics by acquiring images before, during, and after field stimulation applied to the axonal compartment in the presence of either $\beta$-catenin or control siRNA (Fig. 4). Using 14 DIV neurons, we loaded FM dye using KCl-mediated depolarization (Fig. 4B). Initial mean fluorescence of FM dye at FM-loaded puncta within bead ROIs was slightly lower (10\%) in the $\beta$-catenin siRNA axonal compartment than that observed in the control siRNA axonal compartment (mean fluorescence of puncta within bead ROIs for $\beta$-catenin siRNA, $14.86 \pm 0.3821$ a.u., $n=195$ measurements; for control siRNA, $16.57 \pm 0.6902$ a.u., $n=124$; $p<$ $0.05)$. To measure the rate of FM unloading, we monitored fluorescence intensity values at each punctum contained in a bead ROI individually throughout the experiment. We found that reducing axonal $\beta$-catenin expression significantly increased the rate of FM unloading compared with control (Fig. 4B-D).

To eliminate the confound of nonresponding puncta, we determined the time constant, $\tau$, for each punctum by curve fitting
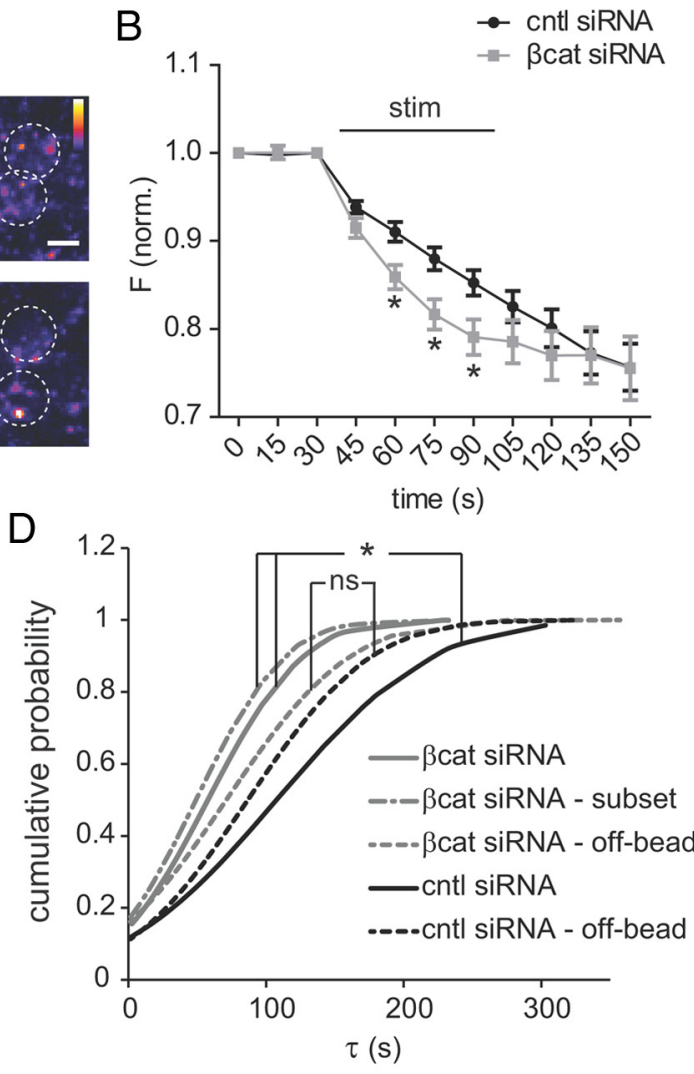

4. Axonal knockdown of $\beta$-catenin alters release properties at nascent presynaptic terminals. $\boldsymbol{A}$, Representative fluo rescentima of the axonal compartment showing FM-loaded puncta at bead ROls. Beads were added $1 \mathrm{~d}$ before imaging. White of $\tau$ values for off-bead FM puncta under $\beta$-catenin siRNA conditions $(n=69)$, under control siRNA $(n=96)$ conditions, and for groups described in $\boldsymbol{C}$. Kolmogorov-Smirnov test, ${ }^{*} p<0.05$. Error bars, SEM.

the unloading kinetics to an exponential decay function and found that $\tau$ was significantly reduced with locally applied $\beta$-catenin siRNA as expected (Fig. $4 C$ ). To ensure that the observed change in rate of unloading was not due to differential loading of the FM dye, we also analyzed a subset of the puncta for the $\beta$-catenin siRNA condition matched to initial FM loading levels for the control siRNA condition (Fig. 4C). This subset of puncta had equivalent unloading kinetics, as did the inclusive $\beta$-catenin siRNA group (Fig. $4 C, D$ ).

As a test for the specificity of the unloading kinetics being related to synaptic activity, we measured puncta dye unloading rates outside the bead ROIs (Fig. 4D). Outside the bead ROIs, dye unloading rates were comparable between conditions and merged toward a common mean value, as would be expected for a nonsynaptic process (Fig. $4 D$ ). Together, these results provide evidence that local $\beta$-catenin synthesis regulates synaptic vesicle release dynamics, providing a novel and previously unreported mechanism for distal presynaptic terminals to alter neurotransmitter release properties following target contact.

\section{Discussion}

Our results suggest that axonal translation plays an essential role in synapse formation. We report the first demonstration of rRNA within mature hippocampal axons and targeting of $\beta$-catenin 
mRNA to nascent presynaptic terminals. We show that $\beta$-catenin mRNA is locally translated and that this translation regulates synaptic vesicle dynamics. How local $\beta$-catenin translation is regulated remains unknown, although the absence of postsynaptic targets in our model system suggests an autonomous presynaptic signal (Andreae et al., 2012). Recent evidence supports the involvement of target-derived signals, including netrin and NT3 in the local translation of $\beta$-catenin in thalamic axons (Pratt et al., 2012) and during the initial outgrowth of hippocampal axons (Kundel et al., 2009). The netrin receptor DCC (deleted in colorectal cancer) has been reported to anchor translational machinery and the clustering of DCC in the absence of netrin may induce low levels of translation (Tcherkezian et al., 2010). There is also some evidence for Wnt signaling in regulation of mRNA translation via GSK3 and mTOR (Ma et al., 2011), though a more well-known role for Wnt signaling is in repressing the constitutive degradation of $\beta$-catenin. Notably, multiple Wnt receptors localize to presynaptic terminals (Varela-Nallar et al., 2009; Sahores et al., 2010). $\beta$-Catenin mRNA is also a putative target for microRNA (Kim et al., 2011) and there are cytoplasmic polyadenylation element-binding sites within $\beta$-catenin's 3'UTR (Kundel et al., 2009).

Using FM dyes to monitor synaptic vesicle exocytosis, we identified a functional role for locally translated $\beta$-catenin in negatively regulating release. A role for $\beta$-catenin in modulating vesicle release has been shown in prior work eliminating $\beta$-catenin cell-wide through conditional genetic deletion (Bamji et al., 2003). In this previous study, cell-wide loss of $\beta$-catenin and presynaptic dysfunction in hippocampal pyramidal neurons were described. As assessed by electron microscopy, $\beta$-catenin knock-out mice showed an increased number of synapses, a reduction in the nondocked synaptic vesicle pool, and no change in the docked pool compared with wild-type mice. Mutant terminals also exhibited a reduction in the replenishment of the readily releasable pool using a prolonged stimulation protocol. These defects were associated with an increase in basal transmission at lower stimulation intensities and consistent with the higher rate of FM release reported here upon local knockdown of $\beta$-catenin.

Our results suggest that presynaptically translated $\beta$-catenin leads to a reduction in the rate of synaptic vesicle release during development of functional boutons and reduced release probability (Branco et al., 2008). This mechanism may underlie the reported reduction in release probability during hippocampal synapse maturation (Bolshakov and Siegelbaum, 1995; Bagley and Westbrook, 2012). Furthermore, a relatively high release probability in postnatal 4-8-d-old rats occludes LTP expression (Bolshakov and Siegelbaum, 1995), suggesting that a mechanism to limit release probability may be necessary for the development of some forms of plasticity. Given the correlation of $\beta$-catenindependent pathways with various diseases (Inestrosa and Toledo, 2008; Maguschak and Ressler, 2008; Klemmer et al., 2011), the regulation of neurotransmitter release properties reported here likely has broad implications for human health.

\section{References}

Aakalu G, Smith WB, Nguyen N, Jiang C, Schuman EM (2001) Dynamic visualization of local protein synthesis in hippocampal neurons. Neuron 30:489-502. CrossRef Medline

Andreae LC, Fredj NB, Burrone J (2012) Independent vesicle pools underlie different modes of release during neuronal development. J Neurosci 32: 1867-1874. CrossRef Medline

Bagley EE, Westbrook GL (2012) Short-term field stimulation mimics synaptic maturation of hippocampal synapses. J Physiol 590:1641-1654. CrossRef Medline

Bamji SX, Shimazu K, Kimes N, Huelsken J, Birchmeier W, Lu B, Reichardt
LF (2003) Role of beta-catenin in synaptic vesicle localization and presynaptic assembly. Neuron 40:719-731. CrossRef Medline

Bolshakov VY, Siegelbaum SA (1995) Regulation of hippocampal transmitter release during development and long-term potentiation. Science 269: 1730-1734. CrossRef Medline

Branco T, Staras K, Darcy KJ, Goda Y (2008) Local dendritic activity sets release probability at hippocampal synapses. Neuron 59:475-485. CrossRef Medline

Fejtova A, Davydova D, Bischof F, Lazarevic V, Altrock WD, Romorini S, Schöne C, Zuschratter W, Kreutz MR, Garner CC, Ziv NE, Gundelfinger ED (2009) Dynein light chain regulates axonal trafficking and synaptic levels of Bassoon. J Cell Biol 185:341-355. CrossRef Medline

Inestrosa NC, Toledo EM (2008) The role of Wnt signaling in neuronal dysfunction in Alzheimer's disease. Mol Neurodegener 3:9. CrossRef Medline

Kim NH, Kim HS, Kim NG, Lee I, Choi HS, Li XY, Kang SE, Cha SY, Ryu JK, Na JM, Park C, Kim K, Lee S, Gumbiner BM, Yook JI, Weiss SJ (2011) p53 and MicroRNA-34 are suppressors of canonical Wnt signaling. Sci Signal 4:ra71. CrossRef Medline

Klemmer P, Meredith RM, Holmgren CD, Klychnikov OI, Stahl-Zeng J, Loos M, van der Schors RC, Wortel J, de Wit H, Spijker S, Rotaru DC, Mansvelder HD, Smit AB, Li KW (2011) Proteomics, ultrastructure, and physiology of hippocampal synapses in a fragile $\mathrm{X}$ syndrome mouse model reveal presynaptic phenotype. J Biol Chem 286:25495-25504. CrossRef Medline

Kundel M, Jones KJ, Shin CY, Wells DG (2009) Cytoplasmic polyadenylation element-binding protein regulates neurotrophin-3-dependent $\beta$-catenin mRNA translation in developing hippocampal neurons. J Neurosci 29:13630-13639. CrossRef Medline

Lucido AL, Suarez Sanchez F, Thostrup P, Kwiatkowski AV, Leal-Ortiz S, Gopalakrishnan G, Liazoghli D, Belkaid W, Lennox RB, Grutter P, Garner CC, Colman DR (2009) Rapid assembly of functional presynaptic boutons triggered by adhesive contacts. J Neurosci 29:12449-12466. CrossRef Medline

Lyles V, Zhao Y, Martin KC (2006) Synapse formation and mRNA localization in cultured Aplysia neurons. Neuron 49:349-356. CrossRef Medline

Ma T, Tzavaras N, Tsokas P, Landau EM, Blitzer RD (2011) Synaptic stimulation of mTOR is mediated by Wnt signaling and regulation of glycogen synthetase kinase-3. J Neurosci 31:17537-17546. CrossRef Medline

Maguschak KA, Ressler KJ (2008) Beta-catenin is required for memory consolidation. Nat Neurosci 11:1319-1326. CrossRef Medline

McAllister AK (2007) Dynamic aspects of CNS synapse formation. Annu Rev Neurosci 30:425-450. CrossRef Medline

Pratt T, Davey JW, Nowakowski TJ, Raasumaa C, Rawlik K, McBride D, Clinton M, Mason JO, Price DJ (2012) The expression and activity of beta-catenin in the thalamus and its projections to the cerebral cortex in the mouse embryo. BMC Neurosci 13:20. CrossRef Medline

Sahores M, Gibb A, Salinas PC (2010) Frizzled-5, a receptor for the synaptic organizer Wnt7a, regulates activity-mediated synaptogenesis. Development 137:2215-2225. CrossRef Medline

Schacher S, Wu F (2002) Synapse formation in the absence of cell bodies requires protein synthesis. J Neurosci 22:1831-1839. Medline

Sebeo J, Hsiao K, Bozdagi O, Dumitriu D, Ge Y, Zhou Q, Benson DL (2009) Requirement for protein synthesis at developing synapses. J Neurosci 29:9778-9793. CrossRef Medline

Taylor AM, Blurton-Jones M, Rhee SW, Cribbs DH, Cotman CW, Jeon NL (2005) A microfluidic culture platform for CNS axonal injury, regeneration and transport. Nat Methods 2:599-605. CrossRef Medline

Taylor AM, Berchtold NC, Perreau VM, Tu CH, Li Jeon N, Cotman CW (2009) Axonal mRNA in uninjured and regenerating cortical mammalian axons. J Neurosci 29:4697-4707. CrossRef Medline

Tcherkezian J, Brittis PA, Thomas F, Roux PP, Flanagan JG (2010) Transmembrane receptor DCC associates with protein synthesis machinery and regulates translation. Cell 141:632-644. CrossRef Medline

Varela-Nallar L, Grabowski CP, Alfaro IE, Alvarez AR, Inestrosa NC (2009) Role of the Wnt receptor Frizzled-1 in presynaptic differentiation and function. Neural Dev 4:41. CrossRef Medline

Zivraj KH, Tung YC, Piper M, Gumy L, Fawcett JW, Yeo GS, Holt CE (2010) Subcellular profiling reveals distinct and developmentally regulated repertoire of growth cone mRNAs. J Neurosci 30:15464-15478. CrossRef Medline 